\title{
Tujuan pendidikan Islam menurut Ibnu Qayyim al Jauziyyah dalam kitab tuhfatu al-maudūd bi ahkāmi al- maulūd
}

\author{
Suhartono a,1, ${ }^{*}$, Yuswani a,2, Faiz Naufal a,3 \\ a Sekolah Tinggi Ilmu Tarbiyah Madani Yogyakarta, Yogyakarta, Indonesia; \\ *1 suhartono.abuhasna@gmail.com; ${ }^{2}$ yuswani12@gmail.com; ${ }^{3}$ faiz.syafaat98@gmail.com \\ Received: \\ Revised: \\ Accepted:
}

KAT A KUNCI

Tujuan

Pendidikan Islam

Ibnu Qayyim
KEYWORDS

Purpose

Islamic Education

Ibn Qayyim
ABSTRAK

Penelitian ini termasuk penelitian literature, memaparkan dan menganalisa pemikiran dan pandangan Ibnu Qayyim Al-Jauziyah terkait tujuan pedidikan Islam dalam kitab Tuhfatu Al Maudūd Bi Ahkāmi Al Maulūd. Analisis data yang digunakan adalah diskriptif kualitatif. Latar belakang penelitian ini bahwa keberhasilan mencapai tujuan pendidikan merupakan hal mutlak yang harus diperhatikan, karena pendidikan dapat dikatakan berhasil apabila telah tercapai apa yang telah ditetapkan sebagai tujuannya. Adapun tujuan penulisan makalah ini untuk mengetahui tujuan pendidikan Islam menurut Ibnu Qayyim al Jauziyah. Hasil penelitian ini menunjukkan bahwa tujuan utama pendidikan Islam menurut Ibnu Qayyim al Jauziyah adalah menumbuh kembangkan seluruh potensi anak, memelihara fitrah, dan menjaganya dari penyimpangan serta merealisasikan arti ibadah kepada Allah Ta'ala. Adapun tujuan penunjang dari tujuan utama pendidikan Islam, yaitu; tujuan yang berkaitan dengan jasmani (Ahdaf Jismiyah), pembinaan aklhak (Ahdaf Akhlakiyah), pembinaan akal (Ahdaf Fikriyah) dan pembinaan keterampilan/skiil (Ahdaf Maslakiyah).

The purpose of Islamic education according to ibn qayyim al-Jauziyyah in the book of tuhfatu al-maudūd bi ahkāmi almaulūd

This research includes literature research, describing and analyzing the thoughts and views of Ibn Qayyim Al-Jauziyah regarding the objectives of Islamic education in the book Tuhfatu Al Maudūd Bi Ahkāmi Al Maulūd. The data analysis used was descriptive qualitative. The background of this research is that the success in achieving educational goals is an absolute thing that must be considered, because education can be said to be successful if what has been achieved as its goal has been achieved. The purpose of writing this paper is to determine the purpose of Islamic education according to Ibn Qayyim al Jauziyah. The results of this study indicate that the main purpose of Islamic education according to Ibn Qayyim al Jauziyah is to develop all children's potential, maintain fitrah, and protect them from deviations and realize the meaning of worship to Allah Ta'ala. As for the supporting objectives of the main objectives of Islamic education, namely; objectives related to the body (Ahdaf Jismiyah), moral development (Ahdaf Akhlakiyah), intelligence development (Ahdaf Fikriyah) and skill development / skiil (Ahdaf 
Maslakiyah)

This is an open-access article under the CC-BY-SA license.

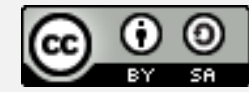

\section{Pendahuluan}

Pendidikan agama Islam telah mengalami pertumbuhan dan perkembangan yang pesat. Hal ini dapat dilihat dari banyaknya lembaga-lembaga pendidikan agama Islam yang telah muncul di berbagai daerah. Hasil dari pendidikan Islam terbentuknya pribadi muslim yang kuat akidahnya, benar dalam ibadah dan baik akhlaknya, berjiwa tenang, akal yang cerdas serta fisik yang kuat guna tercapainya kemuliaan dan kebahagiaan di dunia dan di akhirat.

Di sisi lain arus globalisasi menimbulkan banyak dampak bagi kehidupan manusia, termasuk dalam salah satunya mengenai pendidikan terlebih dalam hal pendidikan agama Islam. Maka perlunya pengkajian secara terus menerus terhadap berbagai pemikiran pendidikan Islam yang menjadi dasar membimbing, mengarahkan dan mengembangkan anak, sehingga tujuan dari pendidikan Islam dapat tercapai secara maksimal. Karena luasnya pembahasan yang berkaitan dengan pendidikan Islam, maka di sini perlu adanya pembatasan masalah, sehingga permasalahan yang dibicarakan tidak meluas. Dalam makalah ini penulis mendeskripsikan atau memaparkan dan menganalisa pandangan Ibnu Qayyim AlJauziyah terkait tujuan pendidikan Islam dalam kitab Tuhfatu Al Maudūd Bi Ahkāmi Al Maulūd.

Penelitian terhadap kitab tersebut telah banyak dilakukan diantarannya pertama; Tesis berjudul "Pendidikan Karakter Prespektif Ibnu Qoyyim dalam kitab "Tuhfatu Al Maudūd Bi Ahkāmi Al Maulūd" yang ditulis oleh Martin. Dalam penelitian tersebut mengkaji tentang pemikiran Ibnu Qayyim mengenai pendidikan karakter, sedangkan dalam makalah ini penulis akan mengkaji pemikiran Ibnu Qayyim tentang tujuan pendidikan Islam. Kedua ; Tesis berjudul " Pemikiran Ibnu Qoyyim tetang pendidikan prenatal dalam kitab "Tuhfatu Al Maudūd Bi Ahkāmi Al Maulūd" yang ditulis oleh Nur Maziyah Ulya. Dalam penelitian tersebut mengkaji tentang pemikiran Ibnu Qayyim mengenai pendidikan prenatal, sedangkan dalam makalah ini penulis akan mengkaji terkait tujuan pendidikan Islam.

\section{Metode}

Jenis penelitian ini tergolong penelitian pustaka (library research), karena semua yang digali adalah bersumber dari pustaka. Untuk pengumpulan data dalam penelitian ini digunakan metode dokumentasi, yaitu mencari data catatan, buku, jurnal dan majalah. Dalam analisis data kualitatif, metode yang digunakan untuk membahas sekaligus sebagai kerangka berpikir pada penelitian ini adalah metode Analisis Konteks, yaitu suatu usaha untuk mengumpulkan dan menyusun data, kemudian diusahakan pula dengan analisa dan interpretasi atau penafsiran terhadap data-data tersebut. 


\section{Hasil dan Pembahasan}

\section{Biografi Ibnu Qayyim Al Jauziyah}

Nama lengkapnya Muhammad bin Abi Bakr bin Ayyub bin Sa"ad bin Haris AzZar"I AdDamasqy. Laqab-nya adalah Syamsudin. Beliau adalah seorang Ahli Fiqih dan ahli fatwa,alImam ar-Rabbani Syaikhul Islam kedua, Kunyahnya adalah Abu Abdillah. Lebih dikenal dengan nama Ibnu Qayyim al-Jauziyyah. Beliau lahir pada tanggal 7 Shafar $691 \mathrm{H}$ dari bapak ibu yang shalih.

Ibnu Qayyim al-Jauziyah hidup dalam asuhan ayahnya yang shalih, Syaikh Qayyim alJauziyah, di tengah lingkungan yang tumbuh subur dengan ilmu pengetahuan.Dari sang ayahlah beliau belajar ilmu faraidh (ilmuwaris), Banyak literatur mengenai biografi Ibnul Qayyim yang mencantumkan beberapa anggota keluarga beliau. Seperti kemenakan beliau, yaitu Abul Fida Imaduddin Isma'il bin Zainuddin yang mengelola sebagian besar perpustakaan milik pamannya ini serta putra-putra beliau, yaitu Abdullah dan Ibrahim mereka semua terkenal sebagai ulama dan para penuntut ilmu. Semenjak kecil, Ibnu Qayyim al-Jauziyah terkenal sangat senang menuntut ilmu. Beliau menuntut ilmu sejak usia tujuh tahun, sebagai buktinya bahwa Beliau pernah belajar kepada asy-Syihab, seorang ahli ta'bir mimpi yang wafat pada tahun $697 \mathrm{H}$. Beliau berkata tentang gurunya ini: "Aku mendengar dari guruku ini beberapa juz, namun aku belum sempat menuntaskanilmu tersebut (ta'bir mimpi) karena usiaku yang masih belia dan dekatnya ajal beliau, semoga Allah merahmatinya. 2

lbnu Qayyim al-Jauziyah sering mengunjungi Kairo untuk berdiskusi dan menuntut ilmu. Hal ini sebagaimana ditegaskan oleh al-Maqrizi, "Beliau sering mengunjungi Kairo Jelasnya. Ibnu al-Qayyim berkata: "Suatu hari akupernah berdiskusi dengan beberapa orang ahli kedokteran di Mesir. Beliau juga berkata: "Aku juga pernah melakukan debat dengan seorang pemuka dancendekiawan terbesar yang ditunjuk oleh kaum Yahudi di Mesir. Beliau pernah berkunjung ke Baitul Maqdis untuk memberikan beberapa pelajaran, ,dalam hal ini Ibnu alQayyim menuturkan bahwa itulah yang aku lakukan di lQuds'. Beliau juga dikenal dengan kesungguhan dan kegigihannya dalam melakukan penelitian dan pengkajian. 3

\section{Tujuan Pendidikan Islam Ibnu Qayyim Al Jauziyah}

Dalam konteks Islam istilah pendidikan telah dikenal dengan banyak istilah yang beragam yaitu at-tarbiyah, at-ta'lim, dan at-ta'dib. Dari setiap istilah tersebut mempunyai makna yang berbeda-beda. Walaupun dalam beberapa hal mempunyai arti yang sama.

Pertama, al-Tarbiyah Kata tarbiyah berasal dari kata, ربي-يربي - تربية yang berarti memelihara, mendidik, mengasuh. Menurut Ibnu Abdillah Muhammad bin Ahmad al-Anshari al-Qurthubi mengartikan bahwa rabb adalah pemilik, maha memperbaiki, maha mengatur, maha menambah, maha menunaikan. Sedangkan menurut al-Jauhari adalah memberi makan, memelihara, mengasuh. Dalam al-Qur'an kata "rabba" ini digunakan untuk Tuhan, karena Tuhan sifatnya mendidik, mengasuh, memelihara dan pencipta. Tarbiyah menurut Ibnu Qoyyim al- Jauziyah, mencakup tarbiyah qalb (pendidikan hati) dan tarbiyah badan secara sekaligus. Dan beliau menjelaskan kaifiyah (cara) mentarbiyah hati dan badan tersebut. Beliau berkata "Antara hati dan badan sama-sama membutuhkan kepada tarbiyah. Keduanya harus ditumbuhkembangkan dan ditambah gizinya sehingga mampu tumbuh dengan sempurna dan lebih baik dari sebelumnya.

Kedua, al-Ta'lim Kata ta'lim berasal dari kata 'allama yang berarti proses transmisi ilmu pengetahuan atau sama dengan pengajaran, yang sering disebut dengan transfer of knowledge. Menurut Naquib al-Attas adalah proses pengajaran tanpa adanya pengenalan secara mendasar yaitu memberikan atau mengajarkan suatu ilmu pengetahuan kepada peserta didik. 
Ketiga, al-Ta'dib Kata al-ta'dib berasal dari kata 'Adaba yang berarti bersopan santun atau beradab. Seseorang dalam menuntut ilmu harus mempunyai sopan santun agar ilmu sedang dipelajari bisa bermanfaat dan diridloi oleh Allah. Menurut Naquib al Attas ta'dib adalah proses mengenalkan ilmu pengetahuan secara berangsur angsur kepada diri manusia dalam tatanan penciptaan, kemudian membimbing dan mengarahkannya pada pengakuan dan pengenalan kekuasaan, keagungan Allah Ta'ala di dalam tatanan wujud dan keberadaannya. Dari uraian pengertian tentang pendidikan tersebut, dapat dipahami bahwa pendidikan merupakan upaya membimbing, membina dan mengarahkan agar anak mendapatkan kebaikan-kebaikan yang bermanfaat bagi dirinya dalam mempersiapkan serta menjalani kehidupan.

Tujuan utama pendidikan Islam menurut Ibnu Qayyim al Jauziyah adalah menumbuh kembangkan seluruh potensi anak, memelihara fitrah, dan menjaganya dari penyimpangan serta merealisasikan arti ibadah kepada Allah Ta'ala. Karena hal ini sesuai dengan tujuan Allah menciptakan manusia, Allah menciptakan manusia agar beribadah kepada Allah Ta'ala dan ini adalah tujuan utama. Dalam hal ini sebagai perwujudan dari fiman-Nya : ,Dan aku tidak menciptakan jin dan manusia melainkan supaya merekamengabdi kepada-Ku'. QS. Ad Dariyat : 56 Segala aktifitas pendidikan seseorang ketika di dunia yang bisa mendatangkan cinta dan di ridhai Allah akan bernilai ibadah dan pelakunya akan mendapatkan pahala, karena ruang lingkup ibadah mencakup segala dimensi kegiatan manusia.

Ibnu Qayyim menyebutkan bahwa diantara tujuan pendidikan adalah menjaga kesucian (fitrah) manusia dan melindunginya agar tidak jatuh kedalam penyimpangan serta mewujudkan dalam dirinya 'ubudiyah (penghambaan) kepada Allah. Fitrah adalah bawaan dasar manusia. Menurut Hasan Al-Hajjaji : Ibnu Qayyim berpandangan bahwa seorang anak terlahir dalam keadaan fitrah hanya saja anak yang terlahir tersebut tidak mengetahui agama secara terperinci. Ibnul Qayyim sendiri menyatakan bahwa, diantara hal yang sepantasnya diketahui ketika dikatakan bahwa anak terlahir dalam keadaan fitrah, atau islam, atau dalam keadaan Haniif (lurus dan bersih), bukan berarti seorang anak yang ketika lahir dari perut ibunya lantas mengetahui agama dan menginginkannya. Akan tetapi fitrah yang dimaksud adalah fitrah menerima agama islam, sehingga jiwa yang fitrah lazim mempercayai penciptanya dan hanya menyembah kepadaNya, kandungan dan keberlangsungan fitrah tersebut berangsur sedikit demi sedikit menyesuikan kesempurnaannya dan apabila hal itu selamat dari berbagai bentuk penyimpangan. Disamping tujuan utama pendidikan Islam tersebut diatas Ibnu Qoyyim juga menjelaskan tujuan- tujuan yang dapat dikatakan sebagai penunjang dari tujuan utama pendidikan Islam, yaitu:

a. Tujuan yang berkaitan dengan jasmani (Ahdaf Jismiyah)

Maksudnya diadakan tarbiyah adalah untuk menjaga kesehatan badan anak, Termasuk dari ahdaf jismiyah yang hendak diwujudkan oleh kerja tarbiyah adalah selalu memperhatikan anak dan mengawasinya dalam hal makan dan minumnya, sebagaimana yang diwasiatkan oleh Ibnu Qayyim Rahimullah berikut ini : "Hendaklah para orang tua itu tidak membiarkan anak-anaknya mengkonsumsi makanan dan minuman yang berlebihan, demikian pula seorang anak harus benar-benar dijauhkan dari bahaya syahwat yang berkaitan dengan perut. Berikutnya, anak-anak tersebut harus diwaspadai betul dari adanya kemungkinan mengkonsumsi sesuatu yang memabukan ataupun yang lainnya yang dapat menghilangkan akal sehat mereka." Pendidikan jasmani berguna untuk menyuburkan, menyehatkan tubuh serta berfungsi sebagaimana mestinya. kebiasaan-kebiasaan yang mengarah pada perkembangan dan pertumbuhan fisik, seperti kebersihan, latihan jasmani dan juga penampilan yang baik, pendidikan jasmani mengacu pada perlakuan terhadap jasmani yang relevan dengan kekuatan fisik. Jasmani yang sehat menjadikan kesempatan melaksanakan aktifitas lebih maksimal baik untuk urusan keduniaan maupun dalam beribadah kepada Allah Ta'ala. 
b. Tujuan yang berkaitan dengan pembinaan aklhak (Ahdaf Akhlakiyah)

Menurut Ibnu Qayyim -Rahimullah-, seseorang akan meraih kebahagiaan apabila dirinya terhiasi dengan akhlak mulia dan terjauhkannya dari akhlak buruk. Oleh karena itu beliau sangat wanti-wanti menasehati para murabbi (pendidik) agar tidak memberi kesempatan kepada anak didiknya untuk berkhianat dan berbohong, sebab khianat dan kebohongan akan merusak bangunan kebahagiaan jiwanya, sebagaimana pernyataan beliau kepada orang tua berikut ini. Menjauhkan anak dari kebiasaan berbohong dan berkhianat itu lebih utama daripada menjauhkannya dari racun yang mematikan.Sebab, ketika ia telah terbiasa berbohong dan berkhianat, maka akan hancurlah kebahagiaannya di dunia dan akhirat, serta dia pun akan terhalang dari berbagai macam kebaikan.

Akhlak dalam pendidikan agama Islam menempati posisi yang sangat penting, salah satu tujuan terpenting adalah pengembangan akhlak secara komprehensif, meliputi hubungan seseorang dengan Allah Ta'ala maupun dengan dirinya dan sesama, baik secara individual maupun kolektif, begitu pula baik dengan lingkungan. Tujuan pertama mempelajari akhlak adalah karena akhlaklah Rosulullah Muhammad Sholallahu'alaihiwasallam diutus, sesuai dengan sabda beliau yang artinya "Sesungguhnya aku diutus untuk menyempurnakan kemuliaan akhlak", (HR. Abu Hurairah).

Kunci kebahagiaan seseorang ada pada perangai dan karakternya ,ketika seseorang senantiasa membiasakan diri dengan karakter baik, maka hal ini menjadi tanda kebaikannya. Mengenai hal ini Ibnu Qayyim menjelaskan bahwa kebahagian dan kesengsaraan seseorang ada pada perangai dan karakternya, dan tiada yang bisa menggapai kebaikan di dunia dan di akhirat kecuali dengan perangai dan karakter yang baik.

c. Tujuan yang berkaitan dengan pembinaan akal (Ahdaf Fikriyah)

Tarbiyah yang baik ialah yang bertujuan untuk membina dan menjaga anak dan pemikiran anak didiknya. Ibnu Qayyim Rahimahullah menyebutkan masalah ini dalam sebuah pernyataan berikut ini. ,Yang perlu diperhatikan oleh para pendidik adalah agar mereka sama sekali tidak memberi kesempatan kepada anak didiknya untuk berinteraksi dengan sesuatu yang membahayakan dan merusak akalnya, seperti;minum-minuman yang memabukkan atau narkoba. Mereka juga harus diawasi dari kemungkinan bergaul dengan orang yang kerusakan moral, perkataan, dan perbuatannya dikhawatirkan akan mempengaruhinya, karena semua itu akan mengakibatkan mereka celaka. Dan apabila hal itu telah menjadi kebiasaan, akibatnya mereka akan memandang mudah untuk melakukan perbuatan-perbuatan keji, padahal orang yang berbuat keji tidak akan masuk surga.

Karena akal yang diberikan pada manusia ketika dianugerahkan berupa potensi yang belum siap pakai, maka pendidikan akal berarti mengusahakan agar akal tersebut berfungfi maksimal. Potensi akal ini akan berkembang menjadi baik jika disertai dengan pendidikan yang baik pula. Sebaliknya bila potensi dibiarkan akibatnya bisa fatal.

d. Tujuan yang berkaitan dengan pembinaan keterampilan/skiil (Ahdaf Maslakiyah)

Dalam pandangan Ibnu Qayyim - Rahimahullah-tarbiyah harus memiliki tujuan menggali minat, bakat dan keahlian (skill) yang tersimpan dalam diri seorang anak. Kemudian setelah diketahui bakat anaknya, maka segera diadakan pembinaan dan pengarahan kepada bidangbidang yang sesuai dan baik, yang akan mewujudkan kemaslahatan diri dan umat manusia secara keseluruhan.

Setiap pendidik harus cermat dalam menggali setiap potensi dan bakat yang dimiliki oleh masing-masing anak. Sebab setiap anak dilahirkan dengan membawa bakat masingmasing. Asal jangan menggiring anak kepada sesuatu yang diharamkan syariat. Dalam hal ini Ibnu Qayyim berpandangan bahwa, kondisi anak didik yang sepatutnya menjadi perhatian bagi para pendidik adalah salah satunya yaitu mengarahkan mereka kepada kegiatankegiatan yang sesuai dengan bakat dan kesiapan mereka untuk melakukannya, setelah 
diketahui bakatnya, maka sebaiknya jangan dialihkan kepada kegiatan yang lain, selama bakat tersebut tidak menyelesihi syariat agama, artinya bahwa bakat tersebut merupakan perkara yang di perbolehkan oleh agama.

Minat merupakan dorongan atau keinginan dalam diri seseorang pada objek tertentu. Contohnya seperti, minat terhadap olahraga, menulis, pecinta alam. Minat memiliki sifat pribadi atau individual. Artinya, tiap-tiap orang memiliki minat yang dapat saja berbeda dengan minat orang lain. Minat tersebut berhubungan erat dengan motivasi seseorang, minat juga dapat berubah-ubah tergantung pada kebutuhan, pengalaman, bukan bawaan sejak lahir. Faktor yang mempengaruhi munculnya minat seseorang tergantung pada kebutuhan fisik, sosial, emosi, dan juga pengalaman. Minat diawali oleh perasaaan senang dan juga sikap positif. Bakat merupakan kemampuan bawaan yang merupakan potensi yang ada pada setiap individu dan masih perlu dikembangkan supaya dapat terwujud. Bakat melekat sejak lahir yang bersifat laten potensial yaitu dapat tumbuh dan berkembang dengan melakukan latihan-secara terus menerus sehingga bisa mencapai ketrampilan maksimal.

\section{Simpulan}

Pemikiran Ibnu Qayyim terkait tujuan pendidikan Islam meliputi tujuan utama bahwa pendidikan adalah menjaga kesucian (fitrah) manusia dan melindunginya agar tidak jatuh kedalam penyimpangan serta mewujudkan dalam dirinya 'ubudiyah (penghambaan) kepada Allah Ta'ala. Selain itu ada tujuan yang sifatnya sebagai penunjang untuk mencapai tujuan utama yang meliputi tujuan yang berkaitan dengan jasmani agar badan sehat dan kuat, pembinaan aklhak agar anak memiliki akhak mulia, pembinaan akal agar tetap bersih dari pikiran-pikiran yang merusak dan pembinaan keterampilan/skiil sebagai bekal dalam mengarungi kehidupan.

\section{Daftar Pustaka}

Bai, H. (2019). Preparing Teacher Education Students to Integrate Mobile Learning into Elementary Education. TechTrends, 63(6), 723-733. doi: 10.1007/s11528-019-00424-z

Giannakas, F., Papasalouros, A., Kambourakis, G., \& Gritzalis, S. (2019). A comprehensive cybersecurity learning platform for elementary education. Information Security Journal: A Global Perspective, 28(3), 81-106. doi: 10.1080/19393555.2019.1657527

Rahman, R., Sakti, A. W., Widya, R. N., \& Yugafiati, R. (2019). Elementary Education Literacy in the Era of Industrial Revolution 4.0. Proceedings of the Second Conference on Language, Literature, Education, and Culture (ICOLLITE 2018). doi: 10.2991/icollite-18.2019.41

Vink, R. M., van Dommelen, P., van der Pal, S. M., Eekhout, I., Pannebakker, F. D., Klein Velderman, M., Haagmans, M., Mulder, T., \& Dekker, M. (2019). Self-reported adverse childhood experiences and quality of life among children in the two last grades of Dutch elementary education. Child Abuse \& Neglect, 95, 104051. doi: 10.1016/j.chiabu.2019.104051 